\title{
A COMPARISON OF METHODS FOR TRAPPING RICE WEEVILS IN STORED WHEAT
}

\author{
C. W. VAN EPENHUIJSEN, M.J. BENDALL and A. SARTIE ${ }^{1}$ \\ Crop \& Food Research, Private Bag 11 600, Palmerston North, New Zealand \\ ${ }^{1}$ Present address: AgResearch, Private Bag 11 008, Palmerston North \\ Corresponding author: vanepenhuijsenk@crop.cri.nz
}

\begin{abstract}
Rice weevils (Sitophilus oryzae) in bulk-stored wheat grain were trapped over a 14-week period to enable weevil numbers to be estimated. Three different trapping methods were used: a grain spear, cone traps and grain probes. The cone traps gave the best indication of the populations of adult weevils present in the grain, although significant relationships between catch number and actual populations were established for all traps. When juveniles were present in the grain none of the traps gave an accurate prediction of actual weevil numbers present. The numbers caught in individual traps at similar population levels varied, which indicates that several traps should be set in each grain lot to give satisfactory estimations of weevil populations. The use of cone traps in commercial practice requires further investigation.
\end{abstract}

Keywords: cone trap, grain probe, grain spear, rice weevil, Sitophylus oryzae.

\section{INTRODUCTION}

Insect activity in stored grain encourages the development of a range of fungal pathogens, many of which produce mycotoxins capable of causing carcinogenic and genotoxic diseases and disorders in animals and humans who consume mouldy grains or grain products (Mabbett 2002).

Stored grain insects do not infest crops in the field and, with a few exceptions, do not normally enter grain once it is in storage (Hagstrum et al. 1996b). Common sources of infestation are residues of grain in empty bins and silos, equipment and transportation vehicles (Phillips et al. 1999). Insect infestations of large bulks of grain usually depend on length of storage time and conditions, as space and food supply are unlimited (Heather 1982). The numbers of insects can vary with the duration of storage, grain temperature, moisture content or the sampling method used (Hagstrum et al. 1996a). Rice weevils (Sitophilus oryzae), the major insect problem in grain silos, are usually found on the surface of bulk grain, while other insects are found in the top $0.5 \mathrm{~m}$ of grain mass (Hagstrum 2000).

A number of methods are used to detect the presence of insects in stored grain. Traps can collect insects from a much larger volume of grain than can direct sampling, and probe traps can detect insects where grain samples fail to (Herrman 1998). However, the results of sampling for insects are influenced by the method used and the pest species. For instance, pushing probe traps below the surface of bulk grain may mean that fewer rice weevils are captured (Hagstrum 2000). However, direct and systematic sampling of the grain is best for monitoring the species and numbers of insects that have been caught by traps. Unfortunately, this approach is labour intensive and requires a certain level of skill (Phillips et al. 1999). Only a few sampling programmes for monitoring stored product pests have been documented to assist pest management decisions (Subramanyam \& Hagstrum 1996). Phillips et al. (1999) recommended one live rice weevil per kilogram of grain as an action threshold for control measures. 
Pest trapping is not routinely carried out in bulk grain in New Zealand. Flourmills reject infested wheat on the basis of visual observation, not on estimates of live insect populations. Insecticide treatment of stored grain and other commodities based on pest monitoring, using traps, is increasingly common in the industry in the United Kingdom (Mabbett 2002). In New Zealand farmers often carry out routine spraying of walls, roofs and floors of grain storage facilities, using up to four applications of the insecticide pirimiphos-methyl (Actellic $®)$ to control grain insects. This is often regarded as an unnecessarily high dose of insecticide (A. Carpenter, pers. comm.). When insect-infested grain is sent from farms to mills, it is either rejected if insect levels are too high, or returned to the farmer to be re-treated with pirimiphos-methyl. If insects are still present when the grain reaches the mill a second time, it is treated with phosphine tablets by a pest control company (A. Carpenter, pers. comm.) There is no breakdown of pirimiphos-methyl residues. Cressey et al. (2000) showed that pirimiphos-methyl residues in New Zealand grain products and foods incorporating grain products (e.g. the pastry in meat pies) could result from the application of several insecticide treatments. Chlorpyriphos-methyl residues found in wheat have been traced to grain imported from Australia (A. Carpenter, pers. comm.).

The trial described in this paper evaluated three methods of trapping rice weevils in stored wheat. The aim was to provide information on the most appropriate methods of estimating insect populations in bulk grain, and to support decision-making relating to insecticide applications.

\section{Experimental design}

\section{MATERIALS AND METHODS}

Wheat from different silos was mixed for 4-5 min, and moisture content of the grain was adjusted to $14.5 \%$ by adding distilled water. Moisture content was checked with a Dickey-John meter. Twelve plastic bins (200 litre capacity) were each filled with 150 litres (approximately $130 \mathrm{~kg}$ ) of the mixed wheat on 4 April 2001.

The inside rim of each bin was coated with a $50 \mathrm{~mm}$ wide band of fluon (Orica Australia Ltd) to stop rice weevils from climbing out. Before the lid was placed on each bin, a piece of plastic was placed over the opening and held in place with a stretch nylon cord to maintain the moisture content of the wheat. The bins were placed in a controlled temperature room at $20^{\circ} \mathrm{C}$ with an average relative humidity of $55 \%$.

Three different types of trap were tested.

1. The Bugpit cone trap (Sorex Ltd, USA) was buried $150 \mathrm{~mm}$ below the bulk grain surface. This trap comprises a perforated lid that fits securely over a clear plastic conical-shaped container coated on the top with fluon.

2. The AgriSense-BCS grain probe trap (AgriSense, USA) was pushed $150 \mathrm{~mm}$ below the surface of the wheat using a marked stick. The acrylic cylindrical tube of the trap had small angled holes in the upper two-thirds of its length. Insects entered the probe through these holes and fell into the tube, which was coated with a band of fluon under the rim.

3. The grain spear (Smith Attachments, Ashburton) had an internal diameter of $24 \mathrm{~mm}$ and took a $180 \mathrm{~g}$ grain sample. Approximately $600 \mathrm{~mm}$ of the hollow part of the spear was pushed into the bulk grain at an angle of approximately $45^{\circ}$, which resulted in a sample spanning the range of $200-500 \mathrm{~mm}$ below the surface. The resulting grain sample was poured into a $2 \mathrm{~mm}$ sieve placed over a stainless steel bowl, the rim of which was treated with fluon.

On 10 September 2001 the wheat was verified as weevil free and 25 rice weevils were released into each bin. Each bin was randomly assigned a cone trap, grain probe or grain spear. After a week the number of weevils in each trap was counted. After counting, all trapped weevils were returned to the bins. Then, 25 more male and female weevils (randomly selected from weevil cultures) were added to each bin. The traps were also randomly re-assigned to different bins. This process was repeated for 11 weeks. Each trap was used in each bin once every 3 weeks, so that each consecutive 3 -week block of the trial was of Latin square design. 
To determine when offspring of the weevils would start to emerge, three 0.5 litre glass jars were partly filled with $200 \mathrm{~g}$ of the same wheat used in the bin trial. At the start of the trial, weevils of the same age and source as those released in the bins were added to the jars. The rims of the containers were coated with fluon and the lid of each contained a piece of filter paper. The weevils were allowed to lay eggs in the wheat for 3 days and were then removed. The wheat was checked for emerging weevils twice a week. The appearance of weevils in these jars provided an indication of when the offspring in the bins would appear. After 8 weeks the filter lids were replaced with metal lids when it was realised that the air circulation created by fans in the room could dry out the wheat and delay development of the offspring.

At week 12, the appearance of weevils in the jars indicated that offspring of weevils would be emerging in the bins. To estimate the populations at this time, four randomly selected bins were removed and the weevils they contained were counted after the numbers in the traps had been recorded. This was done by sieving the wheat over a rectangular $395 \times 290 \mathrm{~mm}$ sieve $(2 \mathrm{~mm}$ mesh) lightly pressed into a plastic tray. Both were shaken 10 times backwards and forwards and all weevils in each sample were recorded. This was repeated at week 13, and again at week 14, when the experiment was concluded. In weeks 12-14 the experimental design was kept as close as possible to that of Latin squares. Assessment of the number of weevils in the bins was carried out by taking scoops of $1500 \mathrm{~g}$ of wheat, and sieving and counting as described above.

The three types of trap were allocated to a different bin each week because it was thought that, once the offspring emerged, the number of weevils in each bin might differ widely. Twelve bins, rather than four bins, per trap provided more replication of weevil colonies.

\section{Statistical analyses}

Data recorded before the weevils' offspring appeared (at 12 weeks) were analysed separately from data recorded afterwards. Data of the number of weevils caught over the first 11 weeks were analysed after square root transformation. This modelled the increased variation in the numbers in each trap as the population increased. Parallel curve analysis using the square root of catch numbers was used to determine whether the relationship between the number of weevils caught and the actual number present differed between the traps. Initially, residual maximum likelihood (REML) analysis (Patterson \& Thompson 1971) was used for the analysis, so bin effects and correlations between catch numbers from the same bin could be assessed. However, neither was statistically significant, so linear regression was used. REML was used to detect a rise in catch numbers at the time the juvenile weevils emerged.

\section{RESULTS}

The performance of the traps before offspring were produced was different from that after juveniles appeared so these two periods were considered separately. The equations relating the catch numbers to the actual populations are based on small populations, before the offspring appeared. The form of the relationship between catch numbers and actual populations for larger populations with offspring may differ from that shown here.

\section{Analysis of trap catches before offspring appeared}

The relationship between the number of weevils caught, and the actual number present has been modelled with a quadratic equation of actual number. The rate of increase in catch numbers as the weevil population increased differed between the types of trap. The catch numbers in individual traps varied more as the populations increased (Fig. 1). The relationships between the numbers of weevils caught in traps and the actual weevil population present in the grain for each trap are listed below (figures in parentheses are standard errors).

Cone trap:

Catch number $=(0.900(0.34)+0.01566(0.0020) \times \text { actual number })^{2} ; \mathrm{P}<0.001 ; \mathrm{R}^{2}=58 \%$. Grain probe:

Catch number $=(0.986(0.29)+0.00987(0.0017) \times \text { actual number })^{2} ; \mathrm{P}<0.001 ; \mathrm{R}^{2}=38 \%$. Grain spear:

Catch number $=(0.036(0.20)+0.00722(0.0012) \times \text { actual number })^{2} ; \mathrm{P}<0.001 ; \mathrm{R}^{2}=47 \%$. 
A test for lack of fit revealed that catches were lower than expected at week $7(\mathrm{P}=0.004)$, but there was no systematic lack of fit. The cone traps, having a higher $\mathrm{R}^{2}$ value, gave a more accurate reflection of the actual weevil population in the grain than the other two trap types. In addition, the cone trap showed quite high catch numbers. The grain spear had an $\mathrm{R}^{2}$ that was nearly as high, but catch numbers were very small. If the catch rate was slightly lower (as might be the case in a different setting) the grain spear might not reflect population increases well.

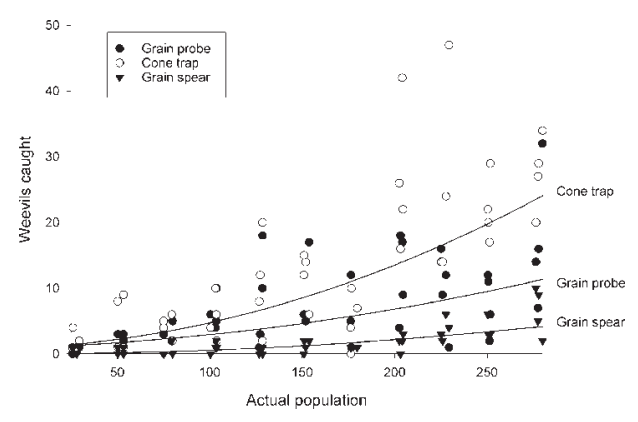

FIGURE 1: Numbers of rice weevils caught in grain plotted against actual weevil populations, for three trap types over 11 weeks. Symbols have been arranged horizontally so that overlaid symbols can be seen.

\section{Analysis of trap catches after the offspring appeared}

Prior to the trial, rearing of rice weevils was carried out at $70 \%$ relative humidity and $27^{\circ} \mathrm{C}$; in these conditions offspring are usually seen after 4 weeks. The temperature in the controlled temperature room was $20^{\circ} \mathrm{C}$ and $55 \% \mathrm{RH}$, which meant that offspring were expected to be present in the jars after 11 weeks (Heather 1982). This was the case, and between 12 and 14 weeks more weevils emerged.

After the offspring appeared, there was no evidence of a relationship between catch numbers and the actual population (Fig. 2), although catch numbers increased noticeably after the offspring appeared (Table 1). Although the catch numbers did not predict the actual numbers of weevils, the grain probe and the cone traps did detect the emergence of the juvenile weevils (Table 1). Mean catches in the grain probe increased from 17 at week 11 to 36 weevils at week 12, and respective catches in the cone traps increased from 27 to 47 weevils (LSD = 11 weevils) over this period.

TABLE 1: Mean number of weevils caught in traps over the duration of the experiment.

\begin{tabular}{rrrr}
\hline Week & Grain probe & Cone trap & Grain spear \\
\hline 1 & 0.5 & 2.0 & 0.8 \\
2 & 2.3 & 4.8 & 0.5 \\
3 & 3.3 & 4.3 & 0.5 \\
4 & 6.3 & 5.5 & 1.0 \\
5 & 8.0 & 10.5 & 0.5 \\
6 & 10.8 & 11.8 & 1.3 \\
7 & 6.3 & 5.3 & 1.0 \\
8 & 12.0 & 26.5 & 1.8 \\
9 & 9.5 & 24.8 & 3.8 \\
10 & 7.8 & 22.0 & 3.8 \\
11 & 17.3 & 27.5 & 6.5 \\
12 & 35.8 & 47.0 & 4.0 \\
13 & 36.3 & 59.0 & 18.7 \\
14 & 77.0 & 62.0 & 8.0 \\
\hline
\end{tabular}




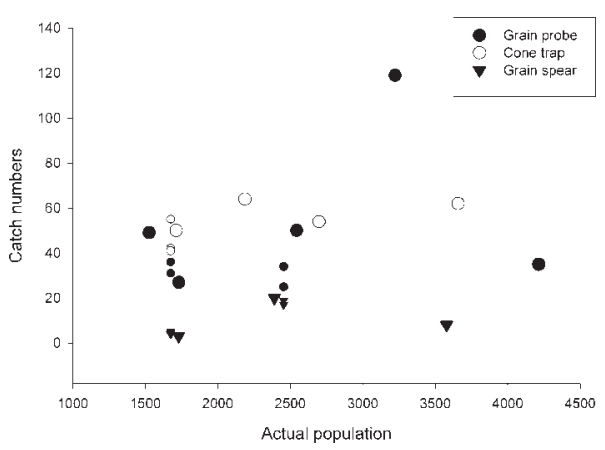

FIGURE 2: Numbers of rice weevils caught in different trap types plotted against actual numbers in stored grain at weeks 12,13 and 14 . Where the actual population has been estimated, data are shown with smaller symbols.

At the end of the trial, the relative humidity in two bins was $77 \%$. The moisture content of the grain was between 15.0 and $16.1 \%$.

\section{DISCUSSION}

The cone traps and the grain probe reflected small changes in weevil populations when 25 weevils were added to the bins each week. However, when the weevils produced offspring, the increase in catch numbers was not commensurate with the estimated population observed in bins that were removed. A possible reason for the lack of reliability of traps in predicting weevil numbers when offspring were present was that the catch rate for juvenile weevils is less than the catch rate for older weevils. The lack of any relationship between catch numbers and actual population could also be due to fewer trap data points during weeks $12-14$ of the trial when bins were being removed. However, the catch numbers in all the traps that were set after the juvenile weevils emerged did not, in general, increase commensurately with the population (Fig. 2 and Table 1). The sex ratio of rice weevils has been reported as not deviating significantly from 1:1 (Evans 1977) so sexual bias is not considered a factor.

The higher moisture content at the end of the trial may have been partly due to the high insect numbers. Very few dead weevils were found in the spear samples, but lack of food in the cone and grain probe traps meant that they contained dead weevils.

While commercial traps for stored grain insects may be expensive, cone traps can be easily and cheaply constructed (Rees 1999). Grain probes and cone traps are easy to use, and do not allow insects to escape. They also provide a mechanism for continuous monitoring of stored-product insects. Detecting low insect populations can give early warning of potential insect problems (Wright et al. 1988). However, regardless of the type of trap used, nil insect catches do not mean that there are no insects in the stored grain since only a small proportion of insects present are captured in the traps. The distribution of weevils throughout grain stores is not uniform, and different traps have differing success in trapping weevils in certain locations (A. Carpenter, pers. comm.). In addition, the traps may only draw weevils from a certain range; therefore research into the number and positioning of traps may also be needed. Of the three traps assessed, the cone trap most accurately reflected the rice weevil populations in stored grain.

In this experiment, four bins with the same type of trap and same actual population could give quite different trap catches. However, the average of the four cone traps gave 
a reasonable indication of weevil population numbers, although catch numbers were variable at higher population levels. Ideally, several traps should be set in each lot of bulk grain, and the average number of weevils per trap should be used to predict the actual weevil population.

More research is needed before the results of this small-scale trial can be confidently applied to an industry recommendation. Similarly, the exact form of the relationship between catch numbers and actual populations may differ for larger populations.

\section{ACKNOWLEDGEMENTS}

We thank Massey University for the use of their experimental mixer, and Dr Patrick Li for technical advice.

\section{REFERENCES}

Cressey, P.; Vannoort, R.; Silvers, K.; Thomson, B. 2000: 1997/98. New Zealand Total Diet Survey. Part 1. Pesticides residues. Ministry of Health, Wellington, New Zealand. p. 27.

Evans, D.E. 1977: The capacity for increase at low temperatures of several Australian populations of Sitophilus oryzae (L.). Aust. J. Ecol. 2: 55-67.

Hagstrum, D.W. 2000: Using five sampling methods to measure insect distribution and abundance in bins storing wheat. J. Stored Prod. Res. 36: 253-262.

Hagstrum, D.W.; Flinn, P.W.; Shuman, D. 1996a: Automated monitoring using acoustical sensors for insects in bin headspace and prediction of infestation level. Environ. Entomol. 23: 1241-1244.

Hagstrum, D.W.; Flinn, P.W.; Howard, R.W. 1996b: Ecology. In: Subramanyam, B.; Hagstrum, D.W. ed. Integrated management of insects in stored products. Marcel Dekker, NY, USA. Pp. 71-134.

Heather, N.W. 1982: Comparison of population growth rates of malathion resistant and susceptible populations of the rice weevil, Sitophilus oryzae (Linnaeus) (Coleoptera: Curculionidae). Queensland J. Agric. Anim. Sci. 39: 61-68.

Herrman, T.J. 1998: Integrated management in grain storage and feed mills. Technical bulletin American Soybean Association. www.asasea.com/technical/ft47-1998. htn $(29 / 07 / 02)$.

Mabbett, T. 2002: Pirimiphos methyl - long term solution to the problem of stored product pests. Int. Pest Control 44 (4): 203-204.

Patterson, H.D.; Thompson, R. 1971: Recovery of inter-block information when block sizes are unequal. Biometrika 58: 545-554.

Phillips, T.W.; Berberet, R.C.; Cuperus, G.W. 1999: Post-harvest integrated pest management. In: Francis, F.J.ed. Encyclopedia of food science and technology, $2^{\text {nd }}$ Edition. Vol. 4. John Wiley \& Sons Inc., NY, USA. Pp. 2690-2701.

Rees, D. 1999: Do-it-yourself traps to monitor storage pests. Australian Grain, Feb/ March. Pp. 3-4.

Subramanyam, B.; Hagstrum, D.W. 1996: Sampling. In: Subramanyam, B.; Hagstrum, D.W. ed. Integrated management of insects in stored products. Marcel Dekker, NY, USA. Pp.135-195.

Wright, V.F.; Mize, T.W.; Pedersen, J.R. 1988: Using insect traps to monitor storedgrain pests on the farm. Proc. XVlll Int. Cong. Entomol. Vancouver, B.C., Canada. p. 443. 